\title{
A smooth changeover and the challenge of managing ICM today
}

\author{
Giuseppe Citerio*
}

(C) 2018 Springer-Verlag GmbH Germany, part of Springer Nature and ESICM

\section{Dear Editor,}

Becoming an editor after Elie Azoulay is quite challenging. It's like becoming the new coach of a team that won the World Cup...you need to be realistic and you can't do much better. Nevertheless, as Michael Jordan suggested, "I can accept failure, everyone fails at something. But I can't accept not trying."... and I'll try to do my best.

In the last 6 years, in fact, the journal profoundly improved its profile and metrics, and is now one of the top three in the category of intensive care journals, and number one among journals dealing only with intensive care topics. The readership, if we consider only the growing number of downloads, has expanded a lot. The article usage, accurately measured by Counting Online Usage of NeTworked Electronic Resources, will surpass 2 million articles downloaded this year. This is partially due to the possibility of accessing all the articles, even if not classically through Open Access, with Springer Nature SharedIt, the content-sharing initiative.

The editorial line defined in the last few years by the Editorial Board will be refined, but the principles in place will remain.

ICM is, and will remain, a critical care journal that publishes clinical studies covering all aspects of critical care. The journal publishes high quality original papers that include critically ill patients with clear messages for all physicians who manage critical care patients. The methodology and the content of original articles, review articles, systematic reviews, and meta-analyses will be evaluated closely for application of high-level methodological standards. ICM will require the authors to fulfill the appropriate Equator (Enhancing the QUAlity and Transparency Of health Research) network checklist

*Correspondence: giuseppe.citerio@unimib.it

School of Medicine and Surgery, University of Milan-Bicocca, Milan, Italy and to respect the International Committee of Medical Journal Editors (ICMJE) requirements. ICM will remain a forum for controversial issues, presenting different opinions from experts. Moreover, we will also be an educational resource for the newer generations, having some review articles, what's new, educational pieces, and images. For images, we are expanding the section to now include short pieces with an attached video. We are also starting to accept short research letters, a forum for communicating early results, proofs of concept, or interesting data on small cohorts. Such contributions are increasingly published and appreciated. ICM will keep its tradition of having thematic issues; the next one, planned in spring 2019, is focused on organ donation and transplants. We do not focus only on science and medicine. In the section "From the Inside", ICM will still receive poetry, personal stories, thoughts and memories, sounding boards, obituaries, or other qualitative materials that authors wish to share with colleagues.

Speed of the review and publication process will remain our hallmark for all articles, not only those designated for the fast track. Manuscripts providing new findings from large interventional studies can still be submitted as 7-day profile publications, allowing important data to be rapidly available in the public domain. The median interval from submission to first decision in 2017, including papers immediately rejected and manuscripts sent out for review, was 6 days, even if in the last few months the number of immediate rejections has decreased because we are facing an increase in the quality of the submitted papers, i.e. higher attractiveness of the journal. More than 7100 authors published at least one article in ICM over the last 5 years. This is really amazing. Thanks to the authors! The speedy review process relies on high quality reviewers, with the more active ones recognized on a Board of Reviewers. Since 2017, ICM has rewarded its reviewers with European CME Credits $\left(\mathrm{ECMEC}^{\circledR} \mathrm{s}\right.$ by the

\section{Springer}


European Accreditation Council for Continuing Medical Education) for their participation in reviewing scientific and educational material.

We are also very fast in the interval from acceptance to online publication (15 days), with a final PDF immediately indexed in PubMed. Thanks to Springer!

The changeover is not only for the Editor in Chief. Many of the esteemed editors will leave the board because their mandate has ended (Jean-François Timsit, Matteo Bassetti, Dominique Benoit, J. Randall Curtis, Gordon Doig, Margaret Herridge, Laurent Papazian, Mark Peters, Daniel Talmor, Antoine Vieillard-Baron). Thanks to all of them for helping the journal to become what it is now, and I'm sure to have their support also for the future. New editors are entering the board and the challenge in the next few months is to again develop an "orchestral spirit", with new instrument players under the direction of a new orchestra director. The incoming editors will increase diversity, covering different subspecialties, geographic provenience, and heterogenous backgrounds. I'm happy to have a talented team working with me. The three Deputy Editors will be Anders Perner, Miet Schetz and Samir Jaber. The Associated Editors' team includes Alain Combes, Anders Aneman, Audrey De Jong, Claudio Sandroni, Garyphallia Poulakou, Geert Meyfroidt, Ignacio Martin-Loeches, Katherine Brown, Manu Shankar-Hari, Michael Darmon, Morten Hylander Møller, Niall Ferguson, Otavio Ranzani, Paul Mayo, Sharon Einav, Thomas Bein, Yaseen Arabi and Sheila Myatra, guest editor for 2019. Twelve of the seventeen are new entries, selected from amongst the reviewers that supported the journal the most in the last few years and for their scientific profile. A warm welcome on board to all of you!

Besides focusing on continuity, we strive for further improvements. The most visible one will be the support of an illustrator to give a uniform style to most of our figures. I hope you will appreciate it. Moreover, a team of junior editors, Peter Buhl Hjortrup, Julie Helms, Chiara Robba, and Emmanuel Weiss, will focus on the new generations' needs and in developing new social media strategies. "Visual abstracts" will become available for most of the original articles and will be part of our communication. A brand new ICM portal, hosted by the ESICM website, will be launched in 2019. Many other slight changes will appear in the next few months. Therefore, follow us and keep an eye on them.

The last point I would like to touch upon is the Impact Factor. Robert F. Kennedy said, "Only those who dare to fail greatly, can ever achieve greatly". When, 6 years ago, Elie Azoulay explained his aim to double the IF...I thought that he was crazy. However, he succeeded, and the IF increased by $270 \%$. The projection we have for the next IF release is still optimistic. Nevertheless, the growth cannot be exponential forever. We will keep an eye on it, but this is not our main driver. The main driver is the readership and the service we are providing to the ICM community and to the ESICM members. This could be read as downloads from the website and with other metrics. Last but not least, thanks to ESICM's support to the journal, while remaining independent in defining its editorial line.

Before concluding this editorial, a great thanks to Elie Azoulay. The actual ICM is the result of thousands of hours of his work. Being the senior deputy editor, I have had the privilege of having a daily interaction with him during the last 6 years. I've learned a lot from him: the massive commitment, the clear vision for the journal, the continuous striving for improvements, the unbiased approach to complex decisions, the attention to details, the respect for the authors and the readership... and the list might be much longer. Thank you, Elie! I know that the mission is almost impossible...but, as you did, we want to try and to succeed in the footsteps you traced by your actions. Quoting Steve Jobs "Stay Hungry. Stay Foolish," but also improve ICM.

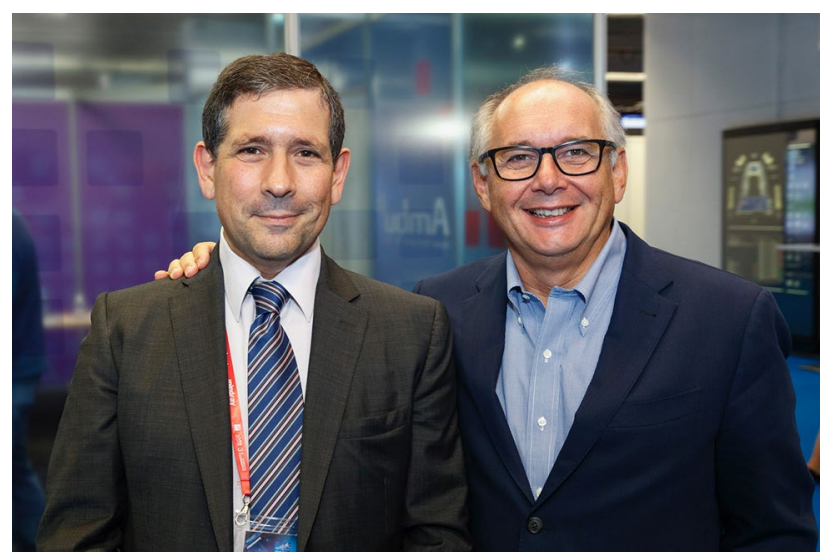

The outgoing Editor-in-Chief, Prof. Elie Azoulay (left), and the incoming Editor-in-Chief, Prof. Giuseppe Citerio (right).

\section{Compliance with ethical standards}

Conflicts of interest

No conflicts of interest for this manuscript.

Received: 9 November 2018 Accepted: 16 November 2018 Published online: 19 December 2018 